\title{
Interview with Laura Eidietis
}

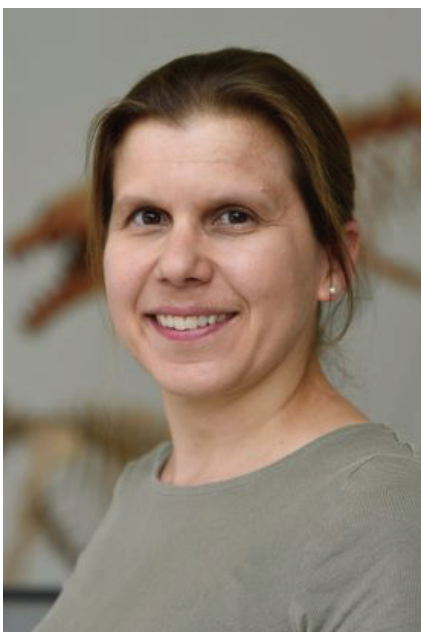

Dr. Laura Eidietis is a Lecturer IV for the Department of Ecology and Evolutionary Biology at the University of Michigan. She received her M.A. in Teaching at the University of Portland in 1999, after which she received her Ph.D. in Biology at the University of Michigan in 2005.

\section{Abhi: What have your pre- vious experiences with research been like?}

Dr. Eidietis: I worked in two different things. I worked in functional morphology, which is a portion of physiology to a certain extent, though it tends to look a bit more at how morphology interacts with physics in the environment. For example, I looked at animals swimming. It was usually more about the biomechanics and less so about the chemistry. That was what I did for my graduate work after being recruited by someone here at Michigan while I was looking for graduate schools. I didn't know what functional morphology was at the time, but I liked physics so it sounded good to me.

In college, I did more molecular work and such. Molecular work when I was in college was a lot newer to a certain extent. It was more labor intensive; it took a lot longer to do things than it does now. You couldn't buy the kits. You had to make your own kits. So that's how I ended up there.

\section{Abhi: How did you decide to pursue a career in academia?}

Dr. Eidietis: When I was working at Eastern, I was actually teaching teachers. Before I went to graduate school for Biology, I got a Master's in Teaching, and I taught for a couple years in 7 th through 12 th grade. As it turns out, there's a real lack of people with any classroom experience who are qualified to teach the science. I actually taught a lot of elementary school teachers science and science methods, which I was really only partially qualified to do because I've never really had a lot of experience working in elementary classrooms. So, it was interesting to see the reality that people that have expertise in elementary classrooms don't really have expertise in science. That's why anyone who has some expertise in science and is willing to learn something about elementary classrooms has a good opportunity to get a reasonable job. What would be ideal would be someone with a Master's in science and a Ph.D. in something to do with elementary education, right? But that just doesn't exist.

So, then I was going to move back here, and this job became open, which is a lecturer position. That's how I got here. Between my curriculum knowledge base and my biology knowledge base, it seemed like it was a good fit. What I did in terms of the teaching originally was what people around here would call a gap year. I didn't know it was going to be a gap year - well it was two years. I thought that maybe at the end that I would be applying to graduate school, but that sort of came after me throwing away all of my graduate school applications. It was kind of a "figure things out" couple of years, and then I decided, "Yes, I actually want to go and learn something about how to science." So, I applied to graduate school and ended up here for 6 years studying tadpoles.

It's kind of a strange, circuitous route, but for someone who really loves teaching, it worked out really well.

\section{Abhi: A key aspect of UMURJ is that we publish across several disciplines and highlight the interdisciplinary nature of research. How important was collaborating across fields and disciplines in your career?}

Dr. Eidietis: When I was doing biology research, there was a lot of collaboration across fields, especially in terms of engineering. I even had an engineer on my dissertation committee. It actually would've been nicer if I could've done more collaboration across fields. My math background was not strong enough, and I didn't feel I had the time to take off for a bunch of math classes. For me, it was mostly important in terms of ideas. I read a lot of 
engineering papers; I talked to a lot of engineers. There was someone in kinesiology who was also very helpful. In terms of what you want to call a cross-field collaboration, that's kind of interesting because my advisor here had a dual appointment in what's now SEAS and EEB. I didn't even think of that as cross-field, but it is, really, in terms of looking at more of a conservation standpoint and then looking at the more basic science standpoint.

When it comes down to it, I work in biology education, which is by nature, something that works across fields. Ideally, I am knowledgeable about the general education, and I am knowledgeable about the actual biological content and concepts. Being able to merge those is interesting. When I did cross into publishing and education, it was a learning experience. It's a different culture. It's a different way of writing. It's a different way of approaching problems.

\section{Abhi: You mentioned a circuitous path towards where you are today. What advice would you have for under- graduates who may be interested in paving a successful academic/research career?}

Dr. Eidietis: The first thing is to be careful about putting blinders on in terms of what successful means. Obviously, if you have this dream of studying atoms or something like that, there are things you will need to do to make that happen, but in a lot of cases, people don't know exactly what it is that they want. It's more a matter of, "I want to do something good. I want to do something useful. I want to do something that I'm good at. I want to do something that makes some sort of mark on the world." My advice is to keep your eyes open in terms of what that means. Don't close doors until you have to.

Try to also get as much of a quantitative background as you can because that math and programming kind of stuff tends to open a lot of opportunities for students that I don't think, particularly in biology, that we do a good job of selling. I think some of the other STEM fields do, but if you have a quantitative skill, you can use that and bring that as a value added to any team that you come to. It makes your potential career much more interesting.
That's another thing I wish someone had told me when I was, you know, a sophomore in college.

\section{Abhi: Our mission is to promote undergraduate research, so how would you characterize the impor- tance or role of undergraduate research from your experience? \\ Dr. Eidietis: I would say I see it in a few different places.} One very important place that I see it in is in preliminary studies. A lot of times within a research group, there are a lot of little studies that need to be done before they can get the money to do the big studies. Those are often short-term things and may or may not pan out into something fruitful enough that someone could make their career on it, but they make really nice undergraduate projects. They're real. They're meaningful. I think the nice thing about being an undergraduate is that although it is nice to get positive results, it's fine if you don't. I think that safety is very useful in creativity and being able to take chances with the research. Unfortunately, I think it's not as obvious because you don't get as many publications out of it and so on and so forth. But the undergraduate researcher gets trained, and the research group moves forward faster when that happens well. I think that's a really good thing that undergraduate research can do.

When I take on an undergraduate, my key is to make sure this person is be able to do research in the future, whether or not this thing that they do right now is actually authentically useful. I want them to learn some skills so that they can do this in the future. I want them to have the opportunity to muck up. I think that's really important because that undergraduate researcher is going to be our graduate student coming up, and I don't want them to mess up when they're a Master's student and fall out of the pipeline. I want them to be able to mess up when they're an undergraduate and are still able to get their credit and get their degree but make the intellectual mistakes that people need to make before they can make the right decisions. 